\title{
Youths' Perceptions Of The Relation Between Alcohol Consumption And Risky Sexual Behaviour in the Western Cape, South Africa: A Qualitative Study
}

\author{
Cassandra Carels $^{1}$ (D) Maria Florence ${ }^{1}$ (D) Sabirah Adams ${ }^{2}$ (D) \\ Deborah Louise Sinclair ${ }^{1,3}$ (D) . Shazly Savahl ${ }^{4}$
}

Accepted: 3 January 2022 /Published online: 20 January 2022

(C) The Author(s), under exclusive licence to Springer Nature B.V. 2022

\begin{abstract}
The purpose of this study is to explore the factors that youth identify as contributing to alcohol consumption, and more specifically its relation to risky sexual behaviour among youth. We employed an exploratory qualitative method using focus group discussions with 34 young people between the ages of 18-25-years-old in low socio-economic status communities in the Western Cape province of South Africa. Data were analyzed thematically utilizing Braun and Clarke's (2006) six-step thematic analysis process. We identified two thematic domains pertaining to alcohol consumption and risky sexual behaviour, namely individual and social factors, each comprising three themes. The individual factors thematic domain comprises intrapersonal influences, employment and educational attainment; while the social factors thematic domain includes interpersonal influences, social influences, and hope for the future. Youth living in low socio-economic status communities were thought to be at greater risk of alcohol misuse and subsequent risky behaviour, given the political and social history of marginalisation, systematic oppression, and social inequality. To address alcohol use and risky sexual behavior among youth, we recommend interventions with adolescents, parents or guardians, and the community. More specifically, interventions aimed at adolescents should focus on the transition to young adulthood. Interventions with parents should focus on their role in modelling and potentially regulating alcohol consumption. Finally, community interventions should centre on drinking behaviors, levels of drinking, what constitutes harmful drinking, and how to identify when treatment and recovery support is likely to be required.
\end{abstract}

Keywords young people $\cdot$ youth $\cdot$ alcohol consumption $\cdot$ risky sexual behaviour . sexual risk - qualitative exploratory study - focus group discussions - Western Cape, South Africa

Shazly Savahl

ssavahl@uwc.ac.za

Extended author information available on the last page of the article 


\section{Introduction}

The purpose of this study is to explore the factors that youth identify as contributing to alcohol consumption, and more specifically its relation to risky sexual behaviour among youth in the Western Cape, South Africa. Alcohol use, which refers to the ingestion of alcoholic beverages containing ethyl alcohol (Keller \& Vaillant, 2018) in this study, is the eighth leading risk factor for death and disease, and third for disability respectively, globally (WHO, 2014; Lategan et al., 2017). South Africa has the fifth highest alcohol consumption rate (WHO, 2018) and the highest prevalence of HIV in the world (Bello et al., 2017; Carey et al., 2011; Scott-Sheldon et al., 2012). The perceived effects of alcohol are influenced by historical, mythological, cultural, religious, physiological, pharmacological, expectancy, personal, and legislative factors (Markos, 2005). Alcohol use can be attributed to an interplay of psychological and biological predispositions, and the social and physical environment (Griffiths, 2014). The dynamics of the social and physical environment of many South African communities reflect the historical context of alcohol consumption. Alcohol misuse in South Africa has a longstanding history that has its roots in colonialism, where alcohol was employed as a mechanism of land dispossession and expropriation. This sinister use of alcohol was a key feature of the colonialist armoury and filtered into oppressive practices in apartheid South Africa. For example, through the 'Dop (tot) system' farm workers were paid with poor quality alcohol in lieu of appropriate monetary compensation (Finjord, 2015). In this way, problematic alcohol use became entrenched in the livelihoods of farmworkers and informal settlements (Cloete $\&$ Ramugondo, 2015). The trajectory of problematic alcohol use from colonialism through to contemporary South Africa can be further understood within the context of the apartheid legislation, which characterised the social and political landscape for nearly five decades. Based on a system of institutionalised racism, discrimination and violent oppression, apartheid was experienced as a form of structural violence and domination. These experiences transcend generations resulting in generational trauma, which is a major contributor to a range of problematic behaviours, including substance and alcohol use (Farmer, 2009). Alcohol use thus offered a structured routine and became the primary activity around which many other activities were organised. The emergence of a particular sociality was created - that of 'drinking friendships' and excessive use of alcohol and binge drinking as a norm.

The association between alcohol, sexual risk behaviour and HIV/AIDS is well established (Assaf \& Mallick, 2018; Kalichman et al., 2007; WHO, 2015). Individuals who use alcohol, especially those who drink heavily, are more likely to engage in high-risk sexual behaviour such as having multiple sexual partners, unprotected sex, concurrent sexual partners, transactional sex and physical and sexual violence (Bello et al., 2017; Muchimba et al., 2013; Scott-Sheldon et al., 2012). However, as it may be challenging to determine whether individuals are engaging in these behaviours, sexual risk behaviour is often identified through the diagnosis of an STI or pregnancy (Glen-Spyron, 2015). Risky sexual behaviour 
is a key contributor to the high prevalence of HIV infections, hampering prevention and mitigation strategies (Manyaapelo et al., 2019). In recent years, South Africa has seen an increase in the risky consumption of alcoholic beverages with a higher alcohol content (Bhana, 2015; Parry et al., 2005; Peltzer \& Ramlagan, 2009).

The age group of 18 to 25 -years-old is most vulnerable to engaging in risky behaviour, given increases in alcohol consumption during this period (Clevelanda et al., 2014; SACENDU, 2010). The potential effects of alcohol use are impaired judgement, altered reasoning skills, and a reduction in one's sense of responsibility (Bello et al., 2017; Rehm et al., 2017). In the United States, alcohol is the most commonly used substance among adults between the ages of 18 and 24 (Brown et al., 2016). The risk for experiencing negative sex-related consequences such as contracting HIV/AIDS and other STIs, and unplanned pregnancies within this age cohort are heightened (Cottonham et al., 2018; Painter et al., 2012).

Explanatory frameworks making sense of the relation between alcohol use and sexual behaviour include Social norms, Alcohol Myopia Theory, Alcohol Expectancy Theory, and Social Learning Theory. In Social norms theory, social norms represent internalized social influences that are predictive of behavioral intentions and behaviour. Norms signal what is accepted by a community or society, such that a failure to conform to social norms may lead to disapproval and/or social sanction (Carey et al., 2011). In many South African communities', alcohol use has become a normative part of social engagement, particularly among youth (Bhana, 2015). In this sense, the social and physical environment of the community shapes alcohol consumption and potential problem drinking (Leslie et al., 2015). Therefore, the context in which alcohol is used serves as a risk or protective factor, while the social environment and individual mutually influence each other (Gifford \& Humphreys, 2007). The Alcohol Myopia Theory (Steele \& Josephs, 1990) postulates that alcohol consumption impairs cognitive capacity, disinhibiting the drinker's behaviour and leading to an inability to fully focus on situational cues (Garcia et al., 2019; Harvey \& Tomlinson, 2019; Lac \& Brack, 2018). Thus, individuals who consume alcohol have an increased probability of engaging in risky sex as they are less likely to be aware of less apparent, more distal cues such as STI risk, and are more likely to be prompted by proximal cues such as sexual arousal (Garcia et al., 2019). Alcohol Expectancy Theory refers to the expectations about how alcohol consumption is likely to affect behaviour and lead to desired outcomes as a motivator for drinking (Oei \& Burrow, 2000). It has consistently been associated with alcohol use and risk behaviour in cross-sectional and longitudinal studies (Lee et al., 2020). Relatedly, Social Learning Theory posits that alcohol expectancies can become reinforced, partly owing to the direct experience of intoxication (Wall et al., 2003). Taken together, these perspectives elucidate the interplay of alcohol use and risky sexual behaviour pharmacologically, psychologically, and socially.

While these theories provide frames of understanding for alcohol use and risky sexual behaviour, they do not take into account the historical, contextual, and related systemic issues that drive the 'generational trauma' of alcohol use and increased risky sexual behaviour, particularly in contexts such as South Africa. In this regard, it is important to consider Intersectionality theory and Social Justice 
Theory as it relates to alcohol use and risky (sexual) behaviour. Intersectionality theory was developed by Crenshaw (1989), and further refined by 'Black' feminists in the USA. They critiqued the idea of women as an homogeneous group, arguing that 'Black' women's subjective experiences were influenced by several factors such as race, class, and gender. Intersectionality underscores that an individuals' experiences are founded on multiple identities, with a 'mutually reinforcing' interplay among various aspects of one's identity, such as gender, race, class, sexuality, and socioeconomic status ( $\mathrm{Vu}$ et al., 2019). These identities contour human experience at the individual level, while concurrently interlocking systems of bias and inequality that exist at the macro social-structural level (e.g., sexism, racism, and classism) (Nadan et al., 2015). It highlights interconnected systems of disadvantage or discrimination, and importantly the 'structural systems of oppression' (Vu et al., 2019). The use of Intersectionality theory has gained traction in the fields of health generally, public health, health disparities, and health inequities. Notwithstanding, the numerous pathways of 'intersectional identities' related to health-risk behaviours and effects are ambiguous, and requires further investigation (Demant et al., 2018). Therefore, within the South Africa context, the impact of multiple disadvantaged identities on health outcomes and behaviours (Bauer, 2014), including alcohol use and risky sexual behaviour, is intricate and requires a multifaceted approach (Demant et al., 2018). In line with this, Bowleg (2012) maintained that intersectionality is essential to a public health commitment to social justice. The history of substance use and social justice is contentious, with alcohol and other substances employed as a tool to exploit and oppress those classified to be in 'lower classes' (International Forum for Social Development \& United Nations, 2006). Although various philosophers and scholars have historically contributed to Social Justice Theory, the concept of social justice attracted burgeoning interest after Rawls' (1971) publication, A Theory of Justice. While there is no consensus on a single definition of the concept of Social justice, it is generally understood as a type of justice whereby all people should receive fair treatment, and have equal rights and opportunities; with an equitable apportion of societal benefits (Hemphill, 2015). Five key principles underpinning Social justice are access to resources, equity, participation, diversity, and human rights. Akin to addressing the interrelated disadvantaged multiple identities of individuals using Intersectionality, Social justice is considered a moral imperative, whereby nation-states are required to uphold these key principles for all citizens - essentially the 'social good' (Levin, 2020). Horn (2013, p. 3) applied Powers and Faden's Theory of Social Justice to foetal alcohol syndrome in South Africa, and poignantly notes that disregarding the historical corollaries of institutionalised racism in the country on public health interventions is "to ignore an extensive and complex range of factors that allow this problem to perpetuate. It is to fail to see this as a community and societal problem, rather than just an individual health problem." Within the South African context, an integrated approach using a Social justice and intersectional perspective to research, policy, practice, and treatment of alcohol use must begin by addressing the structural and social determinants of health, as this increases an individual's vulnerabilities and the unequal distribution of alcohol-related harms (Roche et al., 2015). 
While studies have examined the association between drinking patterns and risky sexual behaviors, they have typically employed cross-sectional designs (e.g. Connor et al., 2013; Sönmez et al., 2006). Studies have also focused on similar populations, such as college and university students, predominantly in the global North (Wagenaar et al., 2018). However, the link between alcohol and sexual behaviours in lowand middle-income contexts have not been examined sufficiently (Bello et al., 2017).

Bello et al. (2017) analysed data from a population-based study in inner-city Johannesburg, South Africa, to determine the extent to which alcohol use influences sexual behaviours. Alcohol use was found to be strongly linked to sexual behaviours among men living in hostels and women inhabiting adjacent informal settlements. The authors advocate for a more rigorous approach to interventions at micro- and macro-levels to ameliorate alcohol harms and reduce the alcohol-HIV link, particularly in vulnerable groups.

In a quantitative study in Cape Town, South Africa, the main aim of the study was to describe ethnic differences in AOD use and the related sexual risks for HIV among vulnerable women (Myers et al., 2013). They found that more than one third of women living in disadvantaged contexts reported using alcohol and other drugs (AOD). The participants indicated that they were impaired and had unprotected sex during their last sexual encounter (Myers et al., 2013). Women between the ages of 18 and 33 who use AODs were recruited into a community-based randomized controlled trial to test an HIV risk-reduction intervention. The key findings indicate that there are ethnic differences in patterns of AOD use. The findings suggest a strong need for gender-sensitive risk-reduction interventions in low-income communities with a focus on ethnic differences.

A systematic review conducted by Wagenaar et al. (2018) found that past research has produced mixed results when reporting on alcohol consumption and risky sexual behaviour. The key factors influencing the relation between alcohol consumption and risky sexual behaviour identified in the literature were personality traits, social determinants, and interpersonal factors (Wagenaar et al., 2018). Factors such as self-efficacy, self-regulation, self-awareness, and sensation-seeking were prominent factors that emerged from personality influences. Furthermore, social norms, socio-economic context, and beliefs, as well as the broader environment contribute to alcohol consumption and risky sexual behaviour. Lastly, factors relating to interpersonal aspects focused on how the individual interacts with various other parts of their lives including personal attributes (e.g., age, race, gender and religiosity), family, peers, romantic relationships, and broader risk and protective factors. The review additionally highlights the impact of the socio-political and historical context, which shapes contemporary life trajectories. However, as only a few studies focused on developing countries such as Kenya and South Africa (Abby et al., 2007; Adams et al., 2014; Morojele et al., 2006; Townshend et al., 2014), the results yielded in the systematic review may be limited to the specific contexts of North American, New Zealand and Australian youths' patterns of risky behaviour (Connor et al., 2013; Kuntsche et al., 2005; Rehm et al., 2006).

Moreover, there is a scarcity of qualitative research to provide a more nuanced understanding of the factors that influence the relation between alcohol consumption and risky sexual behaviour within South Africa and Africa more broadly 
(e.g. Morojele et al., 2006). A notable exception within the South African context is a study undertaken by Morojele et al. (2006) that focused on the factors associated with alcohol consumption-related sexual risk behaviour in diverse cultural settings. The sample consisted of adults between the ages of 25 and 44 in a township and a city site in the Gauteng province. The study findings indicate that alcohol consumption before a sexual encounter affected the individual's sex-related feelings and behaviours, including reasoning skills, sexual arousal, sexual desire, inhibitions, judgment, and sense of responsibility. However, these psychoactive effects of alcohol differed among participants depending on moderating conditions, such as: economic, societal/cultural, community, drinking environment and individual (history, spousal relations, employment, expectations) factors.

\subsection{Rationale}

Alcohol consumption has consistently been associated with risky sexual behaviour (Bello et al., 2017). However, there remains a paucity of research that explores the relation between sexual behaviour and alcohol consumption in South Africa (Morojele et al., 2004; Pithey \& Morojele, 2002). Given that the age group of 18-25 years has been identified as most susceptible to risky drinking practices (SACENDU, 2019), it is imperative to explore the link between alcohol consumption and risky sexual behaviour within this cohort. A better understanding of these practices would contribute to a more comprehensive view of the relation between alcohol consumption and risky sexual behaviour (Adams et al., 2014). Furthermore, understanding how and to what extent alcohol consumption is implicated in risky sexual behaviour has important implications for policy development on alcohol regulation, unplanned pregnancies, and sexually transmitted diseases including HIV (Carpenter, 2007; SADHS, 2016). Qualitative research can provide a key link between two related co-morbidities, HIV and alcohol use disorders. The current study qualitatively explores the relation between alcohol use and risky sexual behaviour (Vagenas et al., 2017).

\subsection{Aim}

The overarching aim of the study is to explore the factors that youth identify and understand as contributing to alcohol consumption. Furthermore, the study aims to explore the factors that contribute to the relation between alcohol consumption and risky sexual behaviour among youth.

\section{Method}

The current study employed an exploratory qualitative methodological framework. 


\subsection{Research Context}

The study was conducted in low socio-economic status communities in Cape Town, in the Western Cape province of South Africa. These communities are characterised by inequalities, with limited resources and access to interventions and treatment for alcohol-or-substance-related disorders (Myers et al., 2010), and have high levels of consumption. The Western Cape Government has identified harm caused by alcohol as a priority concern and area for intervention (Western Cape Liquor Authority, 2020). Cape Town, the capital city of the Western Cape, is situated on the southwestern tip of South Africa and is home to an estimated 7005741 people (Statistics South Africa, 2020). The Cape Flats region is a polarised area where affluent suburbs and economic centres present a stark contrast to the overcrowded, disadvantaged township communities (Chopra \& Sanders, 2004) where high levels of substance use and related problems persist (Vellios \& van Walbeek, 2018).

\subsection{Participants and Sampling}

The study sample included 34 young people between the ages of 18 and 25 who participated in four focus group interviews. Participants were purposively sampled via community-based Non-Profit Organizations and a school in communities on the Cape Flats, in which the primary researcher had previously worked and had established working relationships. To be included in the study, participants had to be between the ages of 18 and 25 , and reside in the community from which they were recruited. The sample comprised 19 females and 15 males (participants selfidentified as either male or female). Participants' racial and language characteristics reflected that of the community, which was historically constructed based on race during the apartheid era (Parry \& van Eeden, 2015). Focus group discussions were conducted until saturation was reached (Morse, 1995). The table below offers an overview of the sample that was utilised in the study.

\subsection{Data Collection}

Four focus group discussions were conducted in both English and Afrikaans, and audio-recorded with permission from the participants. Each group participated in a single session, after which saturation was reached. As noted in Table 1, the focus group discussions encompassed the following group delineation: three

Table 1 Sample breakdown

\begin{tabular}{llllr}
\hline Focus Group & Total & Education & Employment status & Age \\
\hline Mixed group 1 & 7 (3 female; 4 male) & Grade 12 students & Scholars & 18 \\
Mixed group 2 & 9 (5 female; 4 male) & Grade 12 students & Employed & $19-25$ \\
Mixed group 3 & 11 (4 female; 7 male) & $>$ Grade 12 & Unemployed & $18-25$ \\
Female group & 7 (7 female) & University students & University students & $23-25$ \\
\hline
\end{tabular}


heterogeneous gender groups consisting of young men and women; and one homogenous group consisting of women, as no male participants had volunteered. A semi-structured interview schedule was utilized that included the following core questions: 1) What do you think the main factors are that lead the youth in this community to use alcohol?; 2) What are some of the negative outcomes of youth using alcohol?; 3) Can you tell me about young people and their sexual behaviour?; and 4) What are your thoughts regarding alcohol consumption and sexual risk behaviour? Several probes were used to elicit depth information.

\subsection{Data Analysis}

The study employed the six-step thematic analysis process put forward by Braun and Clarke (2006). In the first step focus group discussions were audio-recorded and transcribed verbatim by the lead researcher. The transcripts were verified against the audio recordings by members of the research team. In the second step, transcriptions were repeatedly read in search of meaning and patterns in the data. In the third step. and once the researcher had become familiar with the data, initial codes were assigned to the transcripts. The fourth step entailed collating, sorting, and combining identified codes into potential themes. In the fifth step, themes were reviewed and refined into thematic domains and related themes. Themes were further refined and named and, finally, findings were written up.

\subsection{Procedure and Ethics}

Ethics clearance for the study was obtained from the Senate Research Ethics Committee of the University of the Western Cape. Three non-governmental organizations and one school were contacted. The participants were provided with information on the purpose of the study, the nature of their participation, confidentiality, privacy, and the right to withdraw at any time. Participants were required to provide informed consent as well as sign an agreement that the content of the focus group sessions would remain confidential. The focus group discussions were conducted in a quiet and private space (room or classroom) provided by the organization from which participants were recruited. Access to counselling services was made available to participants if required, given the sensitive nature of the topic.

\section{Findings}

We identified two thematic domains pertaining to alcohol consumption and risky sexual behaviour, namely individual and social factors, each comprising three themes. Individual factors encompassed intrapersonal influences and financial security, while the social factors included interpersonal influences and social impacts. While the mixed-gender groups focused on both thematic domains, the female-only group discussed factors involving renegotiating identity, hope for the future and social context in more depth. 


\subsection{Individual Factors Related to Alcohol Consumption and Risky Sexual Behaviour}

\subsubsection{Intrapersonal Influences}

The participants identified certain intrapersonal factors (perception of the self) that related to alcohol consumption and risky sexual behaviour, namely enjoyment, negotiating identity, courage, and lowered inhibitions and impaired judgement. Alcohol consumption for "enjoyment" was related to drinking for "nice times", as well as the atmosphere that is often associated with drinking. The reference to 'nice times' infers a colloquial saying that encompasses engrossing oneself in social and leisure activities, and often implies the lowering of inhibitions. This is evident in the phrases "T-shirt taken off" and "girls are dancing on the table". The use of the term "fun time" alludes to alcohol being part of young people's lives in their communities, and how it enhances enjoyment. These views were predominantly shared by male participants across employment statuses, with female participants agreeing as the discussion unfolded. The intrapersonal influences of alcohol consumption are closely linked to the interpersonal and socia,l and act as a catalyst for the use of alcohol in different social settings, such as house parties, clubs, and bars. Alcohol consumption is related to the social context, relationships, and social norm of alcohol use.

"So speaking about alcohol, like the brother said. It is for the nice times. It is enjoyable for the first time. The friends are together, we drinking, music is playing, T-shirt taken off, the girls are dancing on the table - it is a fun time." [Translated] (Male participant, Mixed-group 1)

"It is true man. That feeling that they had the first time. So it gets you, and you spiral out of control." [Partially translated] (Male participant, Mixedgroup 1)

The use of alcohol, especially in social settings, was associated with the process of negotiating identity. While this negotiation takes place on an intrapersonal level, it is also inseparably linked to social identity and status, group (peer) dynamics, and more broadly related to the historical context of South Africa. Female participants indicated that alcohol consumption by young people was related to perceived elevation in social status among youth. It is important to note that these findings emerged from the female-only focus group, comprising university students. Furthermore, young people within their communities were referred to as having different lived experiences than participants. They indicated that youth often used alcohol to affirm their social identity, and as a way of coping with low self-esteem and a lack of self-confidence, "because when they are drunk it is whereby they can express themselves". The psychoactive effects of alcohol, in turn, lowered inhibitions and acted as a gateway to engage in an array of risky sexual behaviours, serving as a "social lubricant". Participants argued that the subjective effects of alcohol consumption enable youth to assert themselves, while also enabling them to attribute their behaviours to alcohol use without any accountability when intoxicated, "...like oh I was drunk so now I can just blame it on that". 
"I think young people look for sense of identity from alcohol because when they are drunk it is whereby they are able to express themselves. They have low self -esteem when they are sober, and alcohol boosts their self-esteem to do whatever they want to do." (Female, participant, Mixed-group 3)

"I feel like people use it as an excuse. Getting drunk- ... like oh I was drunk so now I can just blame it on that." (Female participant, Female group)

Young people reported that consuming alcohol gave them a sense of courage and confidence, which they referred to as "liquid courage". "Courage" manifested in two distinct ways: as reduced anxiety in social settings (for example, the ability to speak to the opposite sex or socialise in a group) and to prompt the pursuit of sexual activity. The quote by a female participant: "...the action we were longing in the mind...", speaks to an underlying desire to engage in behaviours that they are only able to when under the influence of alcohol. Male participants spoke about themselves as well as 'on behalf' of other males, while female participants engaged with the thought processes leading to engaging in alcohol consumption to create that sense of confidence. No distinction was made across employment status.

"It's all - it gives you a confidence boost man." (Male participant, Mixedgroup 1)

"So when they are drunk whereby it's easy to communicate and make new friends or engage with certain people." (Female participant, Mixed-group 3) "When you drink alcohol, you are confident, and you get turned on so that leads to sex." (Male participant, Mixed-group 3)

"... you know the actions that we do out of alcohol, is the action we were longing in the mind but you don't have the courage to go and stand up and do something, and now when you take that alcohol and drink, its whereby you get that self-confidence to do it..." (Female participant, Mixed-group 3)

In addition to feeling more confident, young people reported that the effects of alcohol intoxication were linked to being more susceptible or receptive to sexual advances. Decisions made while one's judgment is impaired were implicated in engaging in risky sexual relations that may be regretted once sober. Furthermore, violence, i.e. engaging in an altercation while intoxicated was also addressed, for example "If you have beef with somebody, you are more likely to act out on it...", "... and it might get to the point where anything goes..."; the notion of "anything goes" in a sexual context suggests sexual activities with or without consent. Female participants perceived that the person consuming alcohol, as well as those around them, were at risk. The effects of intoxication were likened to a sense of invincibility and manifested as a forcefulness when making sexual advances such that the recipient of the advances experiences a lack of empathy and respect for their boundaries, linking to the occurrence of rape. Furthermore, it is interesting to note that female participants spoke explicitly about gender-based violence, particularly rape culture, whereas male participants spoke about it more ambiguously.

"You lose your morals! Girls become - some girls become so ratchet hey! It's like the liquid courage. If you have beef with somebody, you more likely 
to act out on it .... You remember nothing of the night before." (Female participant, Female group)

"...if my judgment is not clouded I have a choice of who speak with or who I want to do what with. But, once I start drinking or smoking or whatever my judgment is clouded and it might get to the point where anything goes..." (Male participant, Mixed-group 1)

"Not only for the person who is doing it but also for the person it is being done to..." (Female participant, Female group)

"When you drink alcohol, you don't think straight." (Female participant, Mixed-group 3)

"Then on the extreme side, there is also rape. Because with this courage comes feeling invincible and not taking no for an answer. That's when it leads to now I can't turn back, let's do it and I'm not going to turn back and it's now or never and it's just yeah." (Female participant, Female group)

In summary, participants reported that when consuming alcohol, one's inhibitions are lowered, judgement is impaired, and decision-making is altered. These decisions range from feeling sufficiently confident to talk to someone to inappropriate sexual advances, which could lead to sexual violence. Female participants were more direct in their discussions whereas male participants adopted a more passive stance.

\subsubsection{Financial Security}

The extracts below depict a cyclical relationship between financial difficulty, alcohol consumption, and sex-for-money exchanges. On the one hand, participants perceived that the desire for alcohol leads to sex-for-money exchanges. However, reference was also made to broader socio-economic challenges of poverty and economic hardship that drives women, in particular, to engage in these exchanges. The participants considered alcohol consumption to enable women to carry out these exchanges, highlighting the dynamics of gender and alcohol consumption.

"Yes, it does, specifically young women, they will tend to do extreme things whereby they will be able to drink alcohol and sell their bodies so that they can get the finances that they have or they need. So, finance does play a role. In order for you to get those finances you need to drink and sleep with a man" (Female participant, Mixed-group 3).

"Or it gets to the point where you end up prostituting because you know she was talking about prostitution just to get your next fix or your next drink or whatever the case may be" (Male participant, Mixed-group 1)

Participants, both male and female students (university students and school students), emphasised how drinking motives and expectancies had consequences for financial security or lack thereof. The exchange of money for sex and the use of alcohol to numb feelings of guilt and disgust for exchanging sex illustrates the linkage between poverty, alcohol and sex. The participants' narratives highlight the different 
roles adopted by males and females within these for-money sexual exchanges: with men willingly 'providing' the required financial assistance.

\subsection{Social Factors}

\subsubsection{Family Influences}

Female participants reported that modelling the behaviour of parents, siblings, and other adults in the family influenced the use of alcohol. Familial alcohol consumption directly shaped how the participants perceived alcohol consumption. While in some family contexts alcohol exposure occurred at an early age, in other religious families alcohol exposure occurred in adulthood.

"Like different family dynamics influence the way you perceive alcohol is what we spoke about earlier. Like she said, if you have a 17-year-old sister and you are 10 years old and she is including you in all of those things, then obviously you are going to think it's okay no matter what this school is telling you... in some Christian homes, children don't learn about alcohol until they 18-19. Whereas in other homes when they are 5 or 7." (Female participant, Female group) "It's being like advertised through older adults so they see the adults model that and the children think that is right so they go in that lifestyle" (Female participant, Mixed-group 3)

"Also they drink because their mothers do it, their fathers do it and if your big brother does it and he is your role model or your big sister." (Female participant, (Mixed-group 1)

Female participants, across the focus groups, considered parents as central in shaping attitudes and behaviours about alcohol and sex. For example, if young people are taught to drink responsibly from a young age this behaviour continued into adulthood. However, when parents did not engage in discussing risk-taking behaviours with their children, these behaviours often continued into adulthood. Participants identified permissive or neglectful parenting styles as contributory factors to alcohol consumption and risky sexual behaviour. Parental discipline was regarded as important for moulding children's behaviour alongside supportive community involvement in parenting. Participants also expressed that a "small-town mentality" was linked to engaging in risky alcohol consumption. This denoted the tendency to conform to the norms in the community rather than seek out other opportunities. While the term 'small-town mentality', can be viewed as derogatory, this speaks to how communities were created as a result of South Africa's history, and in most instances refers to low socio-economic contexts. These communities are often characterised by a host of social issues including substance use, underage drinking and pregnancy, and high unemployment.

"My mom worked at a wine company. So since we were small, we were taught to drink properly. We were taught to respect alcohol. Then you get the people around me. They have that small-town mentality where that is all they do. If they study, they come from campus, get together with the people 
that is just chilling at home and they drink. Friday night, Saturday night, Sunday- like they drink every single time. I look at alcohol different to what they do. I was taught to respect it." (Female participant, Female group)

"But now you get certain mothers', you cannot reprimand her child. No matter how wrong my child is, even if my child smoked in front of me. That particular mother does not want to hear about any wrongdoing of her child." [Translated] (Female participant, Mixed-group 1)

"I agree with that. Charity begins at home. We must teach the children by listening on their cell phones about sex or situations you can find yourself in that you can end up dead, you can end up in jail, you know? If they're aware, I think they will exercise that" (Male participant, Mixed-Group 2)

Parenting styles coupled with environmental influences were perceived to influence how youth viewed and consumed alcohol. Furthermore, how parents modelled alcohol consumption and related behaviours, were perceived to inform individual behaviour. Close family relationships were deemed important as a protective factor against risky alcohol consumption.

\subsubsection{Social Context}

Participants reported that drinking alcohol at social gatherings was considered a norm. A male participant expressed that the community and their peers taught themthat it is 'cool' to drink. Some participants noted that time was often allotted to drinking rather than developmentally-enriching activities. Alcohol was considered by some participants to be part of the fibre of certain communities, forming part of many individuals' daily routines.

"...I think the reason why they would prefer drinking than doing the homework is because we've been growing up here and we've been seeing people drink. Our minds -young people's minds- have been moulded. Like the people have moulded our personalities. The way we think make us think this is cool because we have been growing up with people doing it and parties and that excites us. Like they say the beer and all that gives you the confidence; that's just why" (Male participant, Mixed-group 2)

The physical and social environment was reported to influence drinking motives and alcohol expectancies such that some contexts promoted risky alcohol consumption and the belief that one cannot have fun without alcohol. This is highlighted by a female participant who perceived alcohol as forming part of alls interaction, and certain consequences are known to accompany alcohol consumption.

"(name of community) has like a culture of alcohol... So a lot of times it's like the easy way out. People feel like there's going to be a better vibe if there is like alcohol involved and it's not always like that. Some people literally don't see themselves having fun if it's not with alcohol...." (Female participant, Female group) 
"Or it becomes like a norm. At (name of university) I know a group of boys that they literally just used to skip classes and drink." (Female participant, Female group)

Participants believed that their environment determined the choices available to them and their future. As youth were confined to their community, they often did not aspire beyond their circumstances. Their life trajectories were constrained by their social contexts, where alcohol consumption held an elevated status. The value of alcohol was so firmly entrenched that for some, being able to afford alcohol every weekend was said to equate to success; further reinforcing the lack of desire to aspire beyond their circumstances. A sense of hopelessness about the future was also expressed. Participants described their communities as spaces characterised by an intergenerational cyclical relation of poverty and social problems. Therefore, as their grandparents and parents drank and had blue-collar jobs, they believed that their futures would be the same; participants thought that youth in their community could often not transcend the environment familiar to them.

"So, like when you in that environment. And also, they don't see a lot - they don't think of oh, I can go to university and I can do this and I can do that, so like that is enough for them. That's like - if I can afford a crate of beer every weekend, my life is successful... Some of them don't have ambition to live past that" [partially translated] (Female participant, Female group)

"About not wanting to achieve anything. At least we have something to say the next morning- like we have to go to class...If they are just sitting at home, there is nothing motivating them to get out of the state that they are in. they will just continue to be in that same cycle over and over because there is nothing changing their perspective..." (Female participant, Female group)

The participants perceived young peoples' life aspirations to be shaped by their community and unless they were afforded alternative life opportunities, some believed that they would remain in a cycle of poverty and social problems.

\subsubsection{Media Influences}

Participants thought that movies influenced risky behaviour through a social learning process in which young people modelled the actions they saw onscreen.

"It's also something we learn in movies, like oh I need a drink. You didn't even know, you always just saw in movies and then like you in matric already and then you like oh I need a drink!" (Female participant, Female group)

Participants perceived a strong relation between the content of music videos young people engaged with and participation in risky sexual behaviour. Music was described as exhibiting goals to aspire to, ("now you also want to do it"), as well as granting permission to engage in this behaviour, ("it's in the video, why can't you do it?"). Furthermore, participants expressed a sense of belonging when listening to certain songs. However, they noted that "media influences you badly". 
“...alcohol. Music videos. Movies. You know that movies where the girls all party and have great times and such memories. Now you also want to do it. It's in the video, why can't you do it?" (Female participant, Mixed-group 2)

"...its always hitting the note here, and you feel you a part of that song...The media influences you badly." [Partially translated] (Male participant, Mixedgroup 2)

Moreover, the type of music listened to and its lyrics, which often contained explicit sexual messages, may act as a precursor to having sexual relations.

“...there's the lyrics. The way they say it. How many drinks will it take till I get you home... it's the same music like that, it affects you, ah that old school. And before you know it you're in that vibe." (Male participant, Mixed-group 2)

Another way in which the media intersected with sexual behaviours and alcohol consumption was through advertising that glamourised alcohol use, leading some to experiment with alcohol at a young age.

"We were watching TV and this advert of flying fish or whatever it was, and she was like when I'm 18, I'm gonna buy me that because it is nice. So it is because of what they see on TV, the way it is advertised. If you look around, if you open the (community newspaper), you switch on the TV, you hear it on the radio. You know, they get told about this stuff. You can try to protect them as much as you want to it doesn't work because when you walk out and switch on the TV it is advertised there for them to see and they make the adverts look so nice" (Female participant, Mixed-group 1)

"So media influences (male participant) ... it influences alcohol and sex together (female participant)." (exchange between male and female participant, Mixed-group 1)

The participants' assertions indicate that the media has a substantial influence on young people's lives. Participants reported that songs, music videos, movies and advertisements shaped how youth viewed alcohol consumption and sexual engagement. The glamorisation of alcohol consumption and sexual risk behaviour were seen as granting permission to engage in this behaviour as it is deemed socially acceptable and something to aspire to in adulthood.

\section{Discussion}

The current study explored the factors that youth identify as contributing to alcohol consumption, and more specifically its relation to risky sexual behaviour among youth in the Western Cape, South Africa. Alcohol is a major obstacle to achieving 13 of the 17 Sustainable Development Goals by 2030. Globally there have been a series of initiatives to reduce harmful alcohol consumption. Despite these interventions, alcohol consumption continues to escalate, and with it, alcohol-related harm (Shield et al., 2020). Constructions of adulthood and its relation to alcohol 
consumption are exemplified in the current study as community norms. In lowincome communities such as the research contexts of the present study, patterns of drinking have been shaped over many generations (Finjord, 2015) and by extension what it means to be an adult and its relation to alcohol consumption is deeply rooted historically. Youth, modelling the behaviour within their households and communities, considered alcohol consumption as a key feature of adulthood. This finding is consistent with Social norms theories whereby the community's social influence is internalised and acted upon (Carey et al., 2011). This finding also exhibits how the drinking context and social environment can serve as a risk or protective factor, which the individual also wields influence over (Gifford \& Humphreys, 2007).

The findings across the discussion groups in this study reveal slight differences across gender, employment status, and age. The female-only group discussed factors involving renegotiating identity, social context, and sexual violence in more depth, while male participants emphasised courage, confidence, and dominance as a result of drinking. Consistent with previous research (Dir et al., 2018), one of the heterogeneous focus groups (mixed-group 1) reported higher incidences of engaging in alcohol risk behaviour and subsequent risky sexual behaviour over other focus groups consisting of older cohort closer to age 25. Mix-group 1 consisted of the youngest participants (18) in the sample, who can be classified as older adolescents entering young adulthood (Dir et al., 2018).

Participants reported that youth also engaged in drinking to enjoy the atmosphere it created, and that celebrating or partying involved sexual behaviour in this context. While all participants agreed with this notion, male participants across employment status emphasized this view. Patrick et al. (2011) explain that social drinking motives, which include drinking to have fun with friends, are the most commonly endorsed. Participants affirmed the new sense of freedom and independence that youth experience after they reach the age of 18, as they adapt to new roles and responsibilities (Lenz, 2001). Youth were perceived to use alcohol as an identity marker for maturity, or a means of 'fitting in' and compensating for lower selfesteem and a lack of confidence. Alcohol was also used to acquire a sense of courage and was termed "liquid courage" in the present study. This sense of courage may be used to initiate conversations with potential partners or socialize, as well as facilitate sexual advances, leading to consensual and non-consensual sex. Youth may view drinking as an adult status symbol, and thus drink to emulate adulthood and show their independence (Brown et al., 2008; Wisconsin., 1962). This is consistent with the participants who indicated that youth in their communities use alcohol to ascertain their status by fitting in and to draw attention to themselves. More recently, Trama (2016), in describing alcohol consumption in young women, described the illusion of liberation and empowerment provided by alcohol. This is consistent with the finding that female participants, particularly university students, perceived an elevation in social status to be related to consuming alcohol.

Consistent with previous literature (Cook \& Clark, 2005; Dingle \& Oei, 1997; Manyaapelo et al., 2016), participants reported an association between consuming large amounts of alcohol and the increased probability of sexual behaviour, owing to impaired judgement. This association is important in a country such as South Africa, which has one of the highest prevalence rates of STIs and HIV/ 
AIDS in the world (Stats SA, 2020). Furthermore, consuming large amounts of alcohol was used as a catalyst to engage in sexual activity. This is in keeping with an earlier study where the disinhibiting quality of alcohol was described in relation to feelings of confidence, eased social interactions, and resultant feelings of being sexually alluring (Trama, 2016). Here it is important to note that while all participants agreed with this idea, male participants spoke broadly about confidence as a result of consuming alcohol, whereas female participants spoke more actively about the thought processes leading to this confidence. This finding was consistent will all participants despite employment status. Furthermore, female participants emphasized the direct potential for harm to oneself as well as others who may experience, for example, sexual assault. In contrast, male participants spoke more passively about the relation between alcohol use and sexual coercion. This finding is supported by Alcohol Myopia Theory, namely that alcohol consumption impairs cognitive capacity, disinhibits and interferes with processing situational cues, thus heightening sexual risk (Garcia et al., 2019; Harvey \& Tomlinson, 2019; Lac \& Brack, 2018; Steele \& Josephs, 1990).

The male and female participants foregrounded that as young people they are at an age where financial independence was important. The demand to provide for themselves, and in many cases for their family, became a daily burden. Consequently, it was not rare for women to 'sell' sex for money and to consume more alcohol to enable them to engage in such an exchange. The participants expressed that alcohol expectancies motivate drinking (Oei \& Burrow, 2000). Environmental factors exerted a profound impact on their choices and their future as they were often not able to set goals beyond their current circumstances, perpetuating and remaining trapped in a cycle of trauma and poverty. Social factors included interpersonal and social influences. Whereas family influences, parenting styles and family beliefs were described as potential protective factors against risky behaviour, they simultaneously served as risk factors. Consistent with previous research (Morrish et al., 2011; Morrongiello et al., 2008), parental views influenced children's and subsequently young peoples' views to shape their behaviours.

Participants reported that drinking alcohol is considered a norm at social gatherings, such that all occasions are celebrated with alcohol, which in turn promotes risky alcohol consumption and the perception that one cannot have fun without alcohol. Participants further stated that within their community, teenage pregnancy and alcohol consumption were prevalent. Thus, there was an expectation that upon reaching a certain age one would engage in these activities. Coupled with this expectation was the widespread availability of alcohol, which is sold legally and illegally. This availability impacts early-onset consumption. The view that alcohol is less harmful than illicit substances together with widespread availability was also believed to contribute to problems with alcohol. This is consistent with earlier findings (Boer \& Mashamba, 2005; Borsari \& Carey, 2001; Jemmott et al., 2007) that family influences, societal pressures, the broader social context of a community, and the laws and regulations that govern or impact that community exert a strong influence on individual behaviour. 
Consistent with Social Learning Theory, it was perceived that media, specifically television and movies, influence drinking and sexual behaviour through a process of modelling the actions of others (Bandura, 2001). Moreover, when initiated during adolescence, these behaviours are predictive of later risk-taking (O'Hara et al., 2013). Further, in keeping with earlier research in the Western Cape, participants perceived a strong relation between the content of music videos and risky sexual behaviour (Swartbooi et al., 2016).

Congruent with research by Ferreira-Borges et al. (2015), participants reported that while the government has the authority to institute stronger alcohol control policies, the revenue it received for the sale of alcohol impeded such change. Alongside legislation, participants identified the potential role of advertising strategies for reducing alcohol consumption.

The current COVID-19 pandemic has had implications for alcohol consumption globally. The relaxation of alcohol control measures and increasing personal distress related to COVID-19 could lead to an increase in alcohol consumption and potentially worsen the patterns of use in the long term (Rehm et al., 2020). In South Africa, a complete ban on sales of alcohol was introduced on three occasions: on 27 March 2020, 12 July 2020 (with immediate effect), and on 28 December 2020 (Navsaria et al., 2021). While controversial, the ban could potentially be the foundation of a more effective alcohol regulatory environment in the future (Parry et al., 2017). However, while the ban did not permit the legal purchase of alcohol, illegal purchases increased despite significantly higher pricing, as did the production of home-brewed alcohol (Mogotsi \& Bearak, 2020). One point of sale for illegal alcohol are unlicensed liquor outlets, which are commonplace in low-income communities (Bowers et al., 2014). Furthermore, the historical legacy of institutionalised racism, structural violence and social oppression, and the resultant high levels of social inequality, poverty, and other overlapping social and health factors, contribute to high levels of alcohol consumption in the Western Cape (Amanuel et al., 2018).

\subsection{Limitations of the Study}

Despite the rich data collected, one of the limitations of the study is that only one homogenous, female-only focus group was conducted. It is plausible, given that the topics of discussion in the female-only group centred on renegotiating identity, hope for the future and social context in more depth, that conducting a male-only focus group may have yielded more nuanced findings. The gendered nature of alcohol consumption, sexual behaviour, and its intersection is an important consideration, and one that is an important avenue for future research in this area. Furthermore, as the research was targeted at low-income communities, we were not able to draw any comparisons between groups. Therefore, it is unknown whether varying factors would have emerged if middle- and high-income communities were included. However, the complexity of recruiting this age group was evident in the sampling process as participants were working, unemployed, or studying. 


\section{Conclusion}

In summary, the present study represents an important step towards informing the sites for intervention regarding alcohol consumption and risky sexual behaviour among youth. The overarching theme from participants was that high rates of alcohol consumption lead to unplanned sexual activity. We recommend that future researchers include male-only focus group discussions, as the input from female and male participants varied in this study. Understanding the unique differences would place those developing interventions and policies in a better position to make informed evidence-based recommendations. Furthermore, comparisons between various socio-economic communities would allow for a greater understanding of needs in these communities, should results yield key differences. We further recommend interventions with adolescents, parents or guardians and the community. Interventions aimed at adolescents should focus on the transition to young adulthood. These efforts should include psychosocial interventions, responsible drinking, sexual responsibility and awareness, and financial responsibility. An intervention strategy targeting school dropout and low self-esteem by using a combination of psychosocial counselling and life skills through sports coaching to engage, motivate and inspire youth from low-income communities has been shown to increase well-being and raise aspirations for the future (School of hard knocks, 2019). Interventions with parents should focus on their role in modelling and regulating alcohol consumption. Parents should also be prepared to engage in dialogue about sexual behaviour. Community interventions should centre on levels of drinking, what constitutes harmful drinking, and how to identify when treatment and recovery support is indicated, despite the prevalence of excessive drinking. The factors that emerged suggest that the drinking context strengthened the relation between alcohol consumption and risky sexual behaviour. Future research should aim to quantitatively explore these factors to gain a better understanding of youths' perceptions of factors that underpin the relation between alcohol consumption and risky sexual behaviour. The availability and accessibility of alcohol remain a major contributing factor to alcohol-related harm. For this reason, there has been a call for amendments to and more stringent enforcement of current policies. Policymakers are encouraged to make use of public support or forums for developments where they may exist, while not being discouraged when particular policies receive resistance from those more affected (Parry et al., 2017). Given the current context of COVID-19, future research should monitor the change in alcohol consumption during and after the pandemic, and its impact on policy developments. Finally, we urge researchers to be mindful of considering the impact of generational trauma, as a consequence of structural violence and institutionalised racism, on young people's patterns of alcohol use and problematic behaviours.

Acknowledgements The authors would like to acknowledge the financial contribution of the National Research Foundation South Africa. 


\section{Declarations}

Conflict of Interest The authors declares that the research was conducted in the absence of any commercial or financial relationships that could be construed as a potential conflict of interest.

\section{References}

Abby, A., Parkhill, M., Buck, P., \& Saenz, C. (2007). Condom use with a casual partner: What distinguishes college students' use when intoxicated? Psychology of Addictive Behaviours, 21(1), 76-83. https://doi.org/10.1037/0893-164X.21.1.76

Adams, S., Savahl, S., Carels, C., Isaacs, S., Brown, Q., Malinga, M., Monageng, B., \& Zozulya, M. (2014). Alcohol consumption and risky sexual behaviour amongst young adults in a low-income community in Cape Town. Journal of Substance Use, 19(1-2), 118-124. https://doi.org/10.3109/ 14659891.2012.754059

Amanuel, H., Morojele, N., \& London, L. (2018). The health and social impacts of easy access to alcohol and exposure to alcohol advertisements among women of childbearing age in urban and rural South Africa. Journal of Studies on Alcohol and Drugs, 79(2), 302-308. https://doi.org/10.15288/ jsad.2018.79.302

Assaf, S., \& Mallick, L. (2018). Event-based analysis of the association between alcohol use and unsafe sex in seven sub-Saharan African countries. International Journal of Alcohol and Drug Research, 7(1), 1-9. https://doi.org/10.7895/ijadr.245

Bandura, A. (2001). Social cognitive theory of mass communication. Media Psychology, 3(3), 265-299. https://doi.org/10.1207/S1532785XMEP0303_03

Bauer, G. R. (2014). Incorporating intersectionality theory into population health research methodology: Challenges and the potential to advance health equity. Social Science and Medicine, 110, 10-17. https://doi.org/10.1016/j.socscimed.2014.03.0221

Bello, B., Moultrie, H., Somji, A., Chersich, M. F., Watts, C., \& Delany-Moretlwe, S. (2017). Alcohol use and sexual risk behaviour among men and women in inner-city Johannesburg, South Africa. BMC Public Health, 17, 548(2017). https://doi.org/10.1186/s12889-017-4350-4

Bhana, A. (2015). A misplaced focus: Harmful drinking patterns in South Africa. Substance Use \& Misuse, 50, 1089-1091. https://doi.org/10.3109/10826084.2015.1007658

Boer, H., \& Mashamba, T. M. (2005). Psychosocial correlates of HIV protection motivation among black adolescents in Venda. South Africa. AIDS Education Prevention, 17(6), 590-602. https://doi.org/ 10.1521/aeap.2005.17.6.590

Bowleg, L. (2012). The problem with the phrase women and minorities: Intersectionality-an important theoretical framework for public health. American Journal of Public Health, 102, 1267-1273. https://doi.org/10.2105/ajph.2012.300750

Borsari, B., \& Carey, K. B. (2001). Peer influences on college drinking: A review of the research. Journal of Substance Abuse, 13(4), 391-424. https://doi.org/10.1016/S0899-3289(01)00098-0

Bowers, L., Alexander, J., Bilgin, H., Botha, M., Dack, C., James, L., Jarrett, M., Jeffery, D., Nijman, H., Owiti, J. A., Papadopoulos, C., Ross, J., Wright, S., \& Stewart, D. (2014). Safewards: The empirical basis of the model and a critical appraisal. Journal of Psychiatric and Mental Health Nursing, 21, 354-364. https://doi.org/10.1111/jpm.12085

Braun, V., \& Clarke, V. (2006). Using thematic analysis in psychology. Qualitative Research in Psychology, 3(2), 77-101. https://doi.org/10.1191/1478088706qp063oa

Brown, J. L., Gause, N., \& Northern, N. (2016). The association between alcohol and sexual risk behaviors among college students: A review. Current Addiction Reports, 3(4), 349-355. https://doi.org/ 10.1007/s40429-016-0125-8

Brown, S. A., McGue, M., Maggs, J., Schulenberg, J., Hingson, R., Swartzwelder, S., Martin, C., Chung, T., Tapert, S. F., Sher, K., Winters, K. C., Lowman, C., \& Murphy, S. (2008). A developmental perspective on alcohol and youths 16 to 20 years of age. Pediatrics, 121(4), S290-S310. https:// doi.org/10.1542/peds.2007-2243D

Carey, K., Scott-Sheldon, L. A. J., Carey, M. P., Cain, D., Mlobeli, R., Vermaak, R., Mthembu, J., Simbayi, L. C., \& Kalichman, S. C. (2011). Community norms for HIV risk behaviors among men in 
a South African township. Journal of Behavioral Medicine, 34(1), 32-40. https://doi.org/10.1007/ s10865-010-9284-6

Carpenter, C. (2007). Youth alcohol use and risky sexual behaviour: Evidence from underage drunk driving laws. Journal of Health Economics, 24(2005), 613-628. https://doi.org/10.1016/j.jhealeco. 2004.09.014

Chopra, M., \& Sanders, D. (2004). From Apartheid to globalisation: Health and social change in South Africa. Hygiea International, 4(1), 153-174. https://doi.org/10.3384/HYGIEA.1403-8668.04411 53

Clevelanda, M., Reavy, R., Mallett, K., Turrisi, R., \& White, H. (2014). Moderating effects of positive parenting and maternal alcohol use on emerging adults' alcohol use: Does living at home matter? Addictive Behaviors, 39(2014), 869-878. https://doi.org/10.1016/j.addbeh.2014.01.028

Connor, J., Psutka, R., Cousins, K., Gray, A., \& Kypri, K. (2013). Risky drinking, risky sex: A national study of New Zealand university students. Alcoholism: Clinical and Experimental Research, 37(11), 1971-1978. https://doi.org/10.1111/acer.12175

Cook, R. L., \& Clark, D. B. (2005). Is there an association between alcohol consumption and sexually transmitted diseases? A systematic review. Sexually Transmitted Diseases, 32(3), 156-164. https:// doi.org/10.1097/01.olq.0000151418.03899.97

Cottonham, D. P., Madson, M. B., Nicholson, B. C., \& Mohn, R. S. (2018). Harmful alcohol use and alcohol-related sex expectancies as predictors of risky sex among African American female college drinkers. Journal of Ethnicity in Substance Abuse, 17(4), 389-400. https://doi.org/10.1080/15332 640.2016.1255580

Crenshaw, K. W. (1989). Demarginalizing the intersection of race and sex: A Black feminist critique of antidiscrimination doctrine, feminist theory and antiracist politics. University of Chicago Legal Forum, 1(8), 139-157.

Demant, D., Oviedo-Trespalacios, O., Carroll, J., Ferris, J. A., Maier, L., Barratt, M. J., \& Winstock, A. R. (2018). Do people with intersecting identities report more high-risk alcohol use and lifetime substance use? International Journal of Public Health, 63(5), 621-630. https://doi.org/10.1007/ s00038-018-1095-5

Dingle, G. A., \& Oei, T. P. (1997). Is alcohol a cofactor of HIV and AIDS? Evidence from immunological and behavioral studies. Psychological Bulletin, 122(1), 56-71. https://doi.org/10.1037/00332909.122.1.56

Ferreira-Borges, C., Esser, S., Dias, T., Babor, E., \& Parry, C. (2015). Alcohol and public health in Africa: Can we prevent alcohol-related harm from increasing? Addiction, 110(9), 1373-9. https:// doi.org/10.1111/add.12916

Finjord, K. (2015). The slavery of alcohol. FASFacts. http://www.fasfacts.org.za/Resources/Article-View/ ArticleId/46/The-Slavery-of-Alcohol

Farmer, P. (2009). On suffering and structural violence: A view from below. Race/Ethnicity: Multidisciplinary Global Contexts, 3(1), 11-28. http://www.jstor.org/stable/25595022

Francis, J. M., Myers, B., Nkosi, S., Petersen Williams, P., Carney, T., Lombard, C., Nel, E., \& Morojele, N. (2019). The prevalence of religiosity and association between religiosity and alcohol use, other drug use, and risky sexual behaviours among grade 8-10 learners in Western Cape. South Africa. Plos One, 14(2), e0211322. https://doi.org/10.1371/journal.pone.0211322

Garcia, T. A., Litt, D. M., Davis, K. C., Norris, J., Kaysen, D., \& Lewis, M. A. (2019). Growing up, hooking up, and drinking: A review of uncommitted sexual behavior and its association with alcohol use and related consequences among adolescents and young adults in the United States. Frontiers in Psychology, 10, 1872. https://doi.org/10.3389/fpsyg.2019.01872

Gifford, E., \& Humphreys, K. (2007). The psychological science of addiction. Addiction, 102(3), 352361. https://doi.org/10.1111/j.1360-0443.2006.01706.x

Glen-Spyron, C. (2015). Risky Sexual Behavior in Adolescence (p. 2015). Belia Vida Centre.

Griffiths, M. (2014). Early maladaptive schemas in development of addictive disorders as parts of the complex addiction jigsaw. International Journal of High Risk Behaviors and Addiction, 3(3), e16746. http://doi:10.5812/ijhrba.16746

Harvey, A. J., \& Tomlinson, D. A. (2019). Alcohol myopia and the distracting effects of hair in face recognition. Journal of Pychopharmacology, 34(2), 237-244. https://doi.org/10.1177/0269881119 882856

Hemphill, B. (2015). Social justice as a moral imperative. The Open Journal of Occupational Therapy, 3(2), 1-7. https://doi.org/10.15453/2168-6408.1150 
International Forum for Social Development \& United Nations. Division for Social Policy and Development. (2006). Social justice in an open world: The role of the United Nations. United Nations.

Jemmott, J. B., Heeren, G., Ngwane, Z., Hewitt, N., Jemmott, L. S., Shell, R., \& O'Leary, A. (2007). Theory of planned behaviour predictors of intention to use condoms among Xhosa adolescents in South Africa. AIDS Care, 19(5), 677-684. https://doi.org/10.1080/09540120601084308

Kalichman, S. C., Simbayi, L. C., Kaufman, M., Cain, D., \& Jooste, S. (2007). Alcohol use and sexual risks for HIV/AIDS in Sub-Saharan Africa: Systematic review of empirical findings. Prevention Science, 8, 141-151. https://doi.org/10.1007/s11121-006-0061-2

Keller, M. \& Vaillant, G. (2018). Alcohol consumption. Encyclopaedia Britannica. https://www.brita nnica.com/topic/alcohol-consumption

Kuntsche, E., Knibbe, R., Gmel, G., \& Engels, R. (2005). Why do young people drink? A review of drinking motives. Clinical Psychology Review, 25, 841-861 doi:10.1016/j. cpr.2005.06.002.

Lac, A., \& Brack, N. (2018). Alcohol expectancies longitudinally predict drinking and the alcohol myopia effects of relief, self-inflation, and excess. Addictive Behaviors, 77, 172-179. https://doi.org/10. 1016/j.addbeh.2017.10.006

Lama, T. P., Kuor Kumoji, E., Ketlogetswe, D., Anderson, M., \& Brahmbhatt, H. (2016). Alcohol consumption and risky sexual behavior among persons attending alcohol consumption venues in Gaborone, Botswana. Prevention Science, 17, 227-236. https://doi.org/10.1007/s11121-015-0607-2

Lategan, B. W., du Preez, R., \& Pentz, C. D. (2017). Socio-demographic insights into South African student drinking behaviour. South African Journal of Higher Education, 31(5), 90-115. https://doi. org/10.20853/31-5-1512

Lee, C. M., Fairlie, A. M., Ramirez, J. J., Patrick, M. E., Luk, J. W., \& Lewis, M. A. (2020). Self-fulfilling prophecies: Documentation of real-world daily alcohol expectancy effects on the experience of specific positive and negative alcohol-related consequences. Psychology of Addictive Behaviors, 34(2), 327-334. https://doi.org/10.1037/adb0000537

Lenz, B. (2001). The transition from adolescence to young adulthood: A theoretical perspective. The Journal of School Nursing, 17(6), 300-306. https://doi.org/10.1177/10598405010170060401

Leslie, H., Ahern, J., Pettifor, A. E., Twine, R., Kahn, K., Gómez-Olivé, F. X., \& Lippman, S. A. (2015). Collective efficacy, alcohol outlet density, and young men's alcohol use in rural South Africa. Health and Place, 34(2015), 190-198. https://doi.org/10.1016/j.healthplace.2015.05.014

Levin, L. (2020). Rethinking social justice: A contemporary challenge for social good. Research on Social Work Practice, 30(2), 186-195. https://doi.org/10.1177/1049731519854161

Manyaapelo, T., Ruiter, R., Nyembezi, A., van den Borne, B., Sifunda, S., \& Reddy, P. (2016). The psychosocial determinants of the intention to avoid sexual engagement when intoxicated among young men in KwaZulu-Natal. South Africa. BMC Public Health, 16, 562. https://doi.org/10.1186/ s12889-016-3219-2

Manyaapelo, T., Van den Borne, B., Ruiter, R.A.C., Sifunda, S. \& Reddy, P. (2019). Effectiveness of a health behavioural intervention aimed at reduction of risky sexual behaviours among young men in the KwaZulu-Natal Province, South Africa. International Journal of Environmental Research and Public Health, 16(11), 1938. http://hdl.handle.net/20.500.11910/14412

Markos, A. R. (2005). Alcohol and sexual behaviour. International Journal of STD \& AIDS, 16(2), 123127. https://doi.org/10.1258/0956462053057639

Mogotsi, B. \& Bearak, M. (2020). South Africa's alcohol ban during lockdown reveals its deadly drinking habits. The Washington Post. https://www.washingtonpost.com/world/africa/south-africa-coron avirus-lockdown-alcohol-ban/2020/05/09/a2b964a2-8eef-11ea-9322-a29e75effc93_story.html

Morojele, N., Kachieng'a, M., Mokokoc, E., Nkokoa, M., Parry, C., Nkowanee, A., Moshiaa, K., \& Saxenae, S. (2006). Alcohol use and sexual behaviour among risky drinkers and bar and shebeen patrons in Gauteng province. South Africa. Social Science \& Medicine, 62(1), 217-227. https://doi. org/10.1016/J.SOCSCIMED.2005.05.031

Morojele, N. K., Kachieng'a, MA., Nkoko, M.A., Moshia, K.M., Mokoko, E., Parry, C.D.H., Mwansa Nkowane, A. \& Saxena, S. (2004). Perceived effects of alcohol use on sexual encounters among adults in South Africa. African Journal of Drug \& Alcohol Studies, 3 (1 \& 2).

Morojele, N. K., Nkosi, S., Kekwaletswe, C. T., Saban, A. \& Parry, C. (2013). Review of research on alcohol and HIV in Sub-Saharan Africa. South African Medical Research Council: Policy Brief, February 2013. http://196.21.144.194/policybriefs/AlcoholSubSaharan.pdf

Morrish, J., Kennedy, P. \& Groff, P. (2011). Parental influence over teen risk-taking: A review of the literature. SMARTRISK: Toronto, ON 
Morrongiello, B. A., Corbett, M., \& Bellissimo, A. (2008). "Do as I say, not as I do": Family influences on children's safety and risk behaviors. Health Psychology, 27, 498-503. https://doi.org/10.1037/ 0278-6133.27.4.498

Morse, J. (1995). The significance of saturation. Qualitative Health Research, 5(2), 147-149. https://doi. org/10.1177/104973239500500201

Muchimba, M., Haberstick, B., Corley, R., \& McQueen, M. (2013). Frequency of alcohol use in adolescence as a marker for subsequent sexual risk behavior in adulthood. Journal of Adolescent Health, 53(2), 215-221. https://doi.org/10.1016/j.jadohealth.2013.02.005

Myers, B., Kline, T., Browne, A. F., Carney, T., Parry, C. D. H., Johnson, K., \& Wechsberg, W. (2013). Ethnic differences in alcohol and drug use and related sexual risks for HIV among vulnerable women in Cape Town, South Africa: Implications for interventions. BMC Public Health, 13, 174. https://doi.org/10.1186/1471-2458-13-174

Myers, B., Louw, J., \& Pasche, S. (2010). Inequitable access to substance abuse treatment services in Cape Town, South Africa. Substance Abuse Treatment, Prevention, and Policy, 5(28). https://doi. org/10.1186/1747-597X-5-28

Nadan, Y., Spilsbury, J. C., \& Korbin, J. E. (2015). Culture and context in understanding child maltreatment: Contributions of intersectionality and neighbourhood-based research. Child Abuse \& Neglect, 41, 40-48. https://doi.org/10.1016/j.chiabu.2014.10.021

Navsaria, P. H., Nicol, A. J., Parry, C. D. H., Matzopoulos, R., Maqungo, S., \& Gaudin, R. (2021). The effect of lockdown on intentional and non-intentional injury during the COVID-19 pandemic in Cape Town, South Africa: A preliminary report. South African Medical Journal, 111(2). https:// doi.org/10.7196/samj.2021.v111i2.15318

Oei, T. P., \& Burrow, T. (2000). Alcohol expectancy and drinking refusal self-efficacy: A test of specificity theory. Addictive Behaviors, 25(4), 499-507. https://doi.org/10.1016/S0306-4603(99)00044-1

O'Hara, R. E., Gibbons, F. X., Li, Z., Gerrard, M., \& Sargent, J. D. (2013). Specificity of early movie effects on adolescent sexual behavior and alcohol use. Social Science \& Medicine, 96, 200-207. https://doi.org/10.1016/j.socscimed.2013.07.032

Painter, J.E., Wingood, G.M., Diclemente, R.J., DePadilla, L.M., \& Simpson-Robinson, L. (2012). College graduation reduces vulnerability to STIs/HIV among African-American young adult women. Women's Health Issues, 3, 303-310. https://doi:10.1016/j.whi.2012.03.001

Parry, C., Pluddemann, A., Steyn, K., Bradshaw, D., Norman, R., \& Laubscher, R. (2005). Alcohol use in South Africa: Findings from the First Demographic and Health Survey (1998). Journal of Studies on Alcohol, 66(1), 91-97. https://doi.org/10.15288/jsa.2005.66.91

Parry, C., Trangenstein, P., Lombard, C., Jernigan, D. H., \& Morojele, N. (2017). Support for alcohol policies from drinkers in the City of Tshwane, South Africa: Data from the International Alcohol Control study. Drug and Alcohol Review, 37(S1), S210-S217. https://doi.org/10.1111/dar.12554

Parry, K., \& van Eeden, A. (2015). Measuring racial residential segregation at different geographic scales in Cape Town and Johannesburg. South African Geographical Journal, 97(1), 31-49. https://doi. org/10.1080/03736245.2014.924868

Patrick, M., Schulenberg, J., O’Malley, P., Johnston, L., \& Bachman, J. (2011). Adolescents' reported reasons for alcohol and marijuana use as predictors of substance use and problems in adulthood. Journal of Studies on Alcohol and Drugs, 72(1), 106-116. https://doi.org/10.15288/jsad.2011.72. 106

Peltzer, K., \& Ramlagan, S. (2009). Alcohol use trends in South Africa. Journal of Social Sciences, 18, 1-12. https://doi.org/10.1080/09718923.2009.11892661

Pithey, A.L., \& Morojele, N.K. (2002). Literature review on alcohol use and sexual risk behaviour in South Africa. A report. Prepared for WHO project alcohol and HIV infection: Development of a methodology to study determinants of sexual risk behaviour among alcohol users in diverse settings. www.mrc.ac.za/adorg/publications.2002.pdf.

Purvis, R. L., Zagenczyk, T. J., \& McCray, G. (2015). What's in it for me? Using expectancy theory and climate to explain stakeholder participation, its direction and intensity. International Journal of Project Management, 33(1), 3-14. https://doi.org/10.1016/j.ijproman.2014.03.003

Rawls, J. (1971). A theory of justice. The Belknap Press of Harvard University Press.

Rehm, J., Gmel Sr., G. E., Gmel, G., Hasan, O. S. M., Imtiaz, S., Popova, S., Probst, C., Reorecke, M., Room, R., Samokhvalov, A. V., Shield, K. D., \& Shuper, P. A. (2017). The relationship between different dimensions of alcohol use and the burden of disease-an update. Addiction, 112, 9681001. https://doi.org/10.1111/add.13757 
Rehm, J., Kilian, C., Ferreira-Borges, C., Jernigan, D., Monteiro, M., Parry, C., Sanchez, Z., \& Manthey, J. (2020). Alcohol use in times of the COVID 19: Implications for monitoring and policy. Drug and Alcohol Review, 39(4), 301-304. https://doi.org/10.1111/dar.13074

Rehm, J., Taylor, B., \& Room, R. (2006). Global burden of disease from alcohol, illicit drugs and tobacco. Drug Alcohol Review, 25(6), 503-513. https://doi.org/10.1080/09595230600944453

School of Hard Knocks. (2019). About: School of Hard Knocks SA. https://www.schoolofhardknocks.co. za/our-vision

Roche, A., Kostadinov, V., Fischer, J., Nicholas, R., O’Rourke, K., Pidd, K., \& Trifonoff, A. (2015). Addressing inequities in alcohol consumption and related harms. Health Promotion International, 30(S2), ii20-ii35, https://doi.10.1093/heapro/dav030

Scott-Sheldon, L., Carey, M., Carey, K., Cain, D., Heirel, O., Mehlomkula, V., Mwaba, K., Simbayi, L., \& Kalichman, S. (2012). Patterns of alcohol use and sexual behaviours among current drinkers in Cape Town. South Africa. Addictive Behaviors, 37(4), 492-497. https://doi.org/10.1016/j.addbeh. 2012.01.002

Shield, K., Manthey, J., Rylett, M., Probst, C., Wettlaufer, A., Parry, C., \& Rehm, J. (2020). National, regional, and global burdens of disease from 2000 to 2016 attributable to alcohol use: A comparative risk assessment study. The Lancet, 5(1), E51-E61. https://doi.org/10.1016/S2468-2667(19) 30231-2

Shisana, O., Rehle, T., Simbayi, L., Zuma, K., Jooste, S., Zungu, N., Labadarios, D., \& Onoya, D. (2014). South African national HIV prevalence, incidence and behaviour survey, 2012. HSRC Press.

Sönmez, S., Apostolopoulos, Y., Yu, C., Yang, S., Mattila, A., \& Yu, L. (2006). Binge drinking and casual sex on spring break. Annals of Tourism Research, 33(4), 895-917. https://doi.org/10.1016/j. annals.2006.06.005

South African Community Epidemiology Network on Drug Use (SACENDU) (2010). Monitoring alcohol and drug abuse treatment admissions in South Africa. https://www.samrc.ac.za/intramuralresearch-units/atod-sacendu.

South African Community Epidemiology Network on Drug Use (SACENDU) (2019). Monitoring alcohol and drug abuse treatment admissions in South Africa. https://www.samrc.ac.za/intramuralresearch-units/atod-sacendu.

South Africa Demographic and Health Survey 2016: Report, National Department of Health (NDoH), Statistics South Africa (Stats SA), South African Medical Research Council (SAMRC), and ICF. https://dhsprogram.com/pubs/pdf/FR337/FR337.pdf

Statistics South Africa. (2020). 2020 Mid-year population estimates. http://www.statssa.gov.za/?p=13453

Swartbooi, C., Savahl, S., Isobell, D., Khan, G., Wagenaar, C., Makonyonga, F., Maseti, T., Parker, L., \& Ramaite, T. (2016). Adolescents' perceptions of health and well-being: Influences of urban contemporary music. Journal of Psychology in Africa, 26(4), 379-383. https://doi.org/10.1080/14330 237.2016.1208958

Townshend, J., Kambouropoulos, N., Griffin, A., Hunt, F., \& Milani, R. (2014). Binge drinking, reflection impulsivity, and unplanned sexual behaviour: Impaired decision-making in young social drinkers. Alcoholism: Clinical and Experimental Research, 38(4), 1143-1150. https://doi.org/10. 1111 /acer. 12333

Trama, S. (2016). Alcoholism in girls: A theoretical framework. Indian Journal of Health \& Wellbeing, 7(12), 1160-1162. http://www.i-scholar.in/index.php/ijhw/article/view/134240

Vagenas, P., Brown, S., Clark, J. L., Konda, K. A., Lama, J. R., Sanchez, J., Duerr, A. C., \& Altice, F. L. (2017). A qualitative assessment of alcohol consumption and sexual risk behaviors among men who have sex with men and transgender women in Peru. Substance Use \& Misuse, 52(7), 831-839. https://doi.org/10.1080/10826084.2016.1264968

Vellios, N. G., \& van Walbeek, C. P. (2018). Self-reported alcohol use and binge drinking in South Africa: Evidence from the National Income Dynamics Study, 2014 - 2015. The South African Medical Journal, 108(1), 33-39. https://doi.org/10.7196/samj.2018.v108i1.12615

Vu, M., Li, J., Haardörfer, R., Windle, M., \& Berg, C. J. (2019). Mental health and substance use among women and men at the intersections of identities and experiences of discrimination: insights from the intersectionality framework. Research on Social Work Practice, 30(2), 186-195. https://doi.org/ 10.1186/s12889-019-6430-0

Wagenaar, C., Florence, M., Adams, S., \& Savahl, S. (2018). Factors impacting on the relationship between alcohol consumption and risky sexual behaviour among young people: A systematic review. Cogent. Psychology, 5(1). https://doi.org/10.1080/23311908.2018.1483049 
Wall, A. M., Thrussell, C., \& Lalonde, R. N. (2003). Do alcohol expectancies become intoxicated outcomes? A test of social-learning theory in a naturalistic bar setting. Addictive Behaviors, 28(7), 1271-1283. https://doi.org/10.1016/S0306-4603(02)00253-8

Western Cape Liquor Authority. (2020). Strategic Plan for 2020 - 2025: Western Province. https://www. wcla.gov.za/sites/default/files/2020-06/2020\%20-\%202025\%20Stategic\%20Plan_0.pdf

Wisconsin. (1962). Reprint of Youthful Drinking and Driving Report from the Wisconsin Legislative Council 1963 Report. The University of Wisconsin.

World Health Organisation (WHO). (2014). Global Status Report on Alcohol and Health. https://www. who.int/substance_abuse/publications/alcohol_2014/en/

World Health Organization. (2015). World Health Statistics reports on global health goals for 194 countries. https://www.who.int/mediacentre/news/releases/2015/world-health-statistics-2015/en/

World Health Organization. (2017). WHO report on the global tobacco epidemic, 2017. https://www. who.int/tobacco/global_report/2017/en/

World Health Organization (WHO) (2018). Global status report on alcohol and health 2018. https:// www.who.int/substance_abuse/publications/global_alcohol_report/en/

Publisher's Note Springer Nature remains neutral with regard to jurisdictional claims in published maps and institutional affiliations.

\section{Authors and Affiliations}

\section{Cassandra Carels $^{1}$ (D) Maria Florence ${ }^{1}$ (D) Sabirah Adams ${ }^{2}$ (iD . Deborah Louise Sinclair ${ }^{1,3}$ (D) Shazly Savahl ${ }^{4}$}

Cassandra Carels

cassandrazcarels@gmail.com

Maria Florence

mflorence@uwc.ac.za

Sabirah Adams

sabirah.adams@uct.ac.za

Deborah Louise Sinclair

deborahlouise.sinclair@ugent.be

1 Department of Psychology, University of the Western Cape, Cape Town, South Africa

2 Centre for Higher Education Development, Language Development Group, University of Cape Town, Cape Town, South Africa

3 Department of Special Needs Education, Ghent University, Ghent, Belgium

4 Centre for Interdisciplinary Studies of Children, Families and Society, University of the Western Cape, Cape Town, South Africa 